\title{
A Research Protocol of Hands-On Healthy Meal Preparation Intervention (Kidchen Study) to Improve Children's Nutritional Outcomes
}

\author{
Satvinder Kaur ${ }^{*}$, Ng Choon Ming1, Koo Hui Chin², Roseline Yap Wai Kuan³, Yim Hip \\ Seng ${ }^{1}$, Firdaus Mukhtar ${ }^{4}$
}

\author{
${ }^{1}$ Faculty of Applied Sciences, UCSI University, 56000 Kuala Lumpur, Malaysia \\ ${ }^{2}$ Faculty of Applied Sciences, Tunku Abdul Rahman University College, 53300 Kuala Lumpur, Malaysia \\ ${ }^{3}$ School of Biosciences, Taylor's University, 47500 Subang Jaya, Selangor, Malaysia \\ ${ }^{4}$ Department of Psychiatry, Faculty of Medicine and Health Sciences, Universiti Putra Malaysia, \\ 43400 Serdang, Selangor, Malaysia
}

\begin{abstract}
The objective of this paper is to describe the protocol of a 12-week hands-on healthy meal preparation intervention among children, up to a 3-month follow-up. The aim of KidChen Study (kids in kitchen) is to improve children's nutritional outcomes. In this randomized-controlled trial, simple random sampling will be used to select schools in Kuala Lumpur, Malaysia. Subsequently, the selected schools $(\mathrm{n}=2)$ will be assigned randomly to either the intervention or control group. The current study will include healthy Malaysian children aged 10-11 years old with no serious disease or food allergy. The intervention is based on Social Cognitive Theory that addresses personal and environmental factors for changing children's behaviour. Children from the intervention group will receive a 60 -minute home food environment module with their parents consisting of nutrition talk, healthy food tasting, parent-child quiz; and five 60 minute interactive hands-on healthy meal preparation modules focusing on core food groups coupled with storytelling sessions to incorporate nutrition education. Outcome measures are children's psychosocial factors towards healthy meal preparation (knowledge, attitude, practice, self-efficacy), dietary behaviour, food consumption pattern, home food availability and anthropometric measures (BMI-for-age z-score, body fat percentage, waist circumference). Repeated measures ANOVA will be used to evaluate the intervention outcomes. KidChen Study is an experiential learning approach to instil a positive attitude towards nutrition and empower children with nutrition skills. We anticipate that the intervention will advocate healthy eating behaviour among children, impacting their nutritional outcomes over time.
\end{abstract}

Keywords: children, healthy meal preparation, intervention, Malaysia, nutrition

\section{INTRODUCTION}

Globally, 340 million children are affected by overweight/obesity problem (WHO 2018). Many did not achieve the recommended dietary guideline for whole grains, vegetables, fruits, legumes and milk (Banfield et al. 2016; Faught et al. 2017). Further, unhealthy eating habits such as snacking, high intakes of fried foods, sugary foods, fast foods and low intakes of fruits and vegetables among school-aged children are now very common (Febriani \& Sudarti 2019; Hoque et al. 2016). The health consequences to this serious epidemic include increased vulnerability of children affected by chronic diseases, adverse effect on a child's development and reduced quality of life, which can track into adulthood
(WHO 2018). Other negative implications include the effect on children's academic performance and psychological health (Rankin et al. 2016).

According to a systematic review and metaanalysis of school-based nutrition interventions among children, nutrition lessons, improvement in the school environment and food marketing did not increase vegetable intake by a useful amount (Evans et al. 2012). In Asia, most studies frequently target behavioural modification through health education lectures and/or physical activity sessions which demonstrated a lack of effect in anthropometry outcomes (Uijtdewilligen et al. 2016). Further, interventions are largely approached in the same way and only repackaged slightly, which is inadequate to address key barriers (The Academy of Medical Sciences

"Corresponding Author: +6016-2029941, email: satvinderkaur@ucsiuniversity.edu.my 
2017). The main basis of interventions is often to increase knowledge and nutrition awareness but the emphasis on experiential learning, increasing motivations and enhancing skills for long term health benefits are minimal.

Since obesity is the result of people responding normally to the obesogenic environment (Swinburn et al. 2011), it is important to equip children with the skills to counteract this epidemic and for the sustainability of healthy behaviours. Recently, there is a global interest to involve children in healthy meal preparation to improve their nutrition. When children prepare healthy meals, there were increased nutrition knowledge, attitude and self-efficacy towards cooking, fruits and vegetable preferences/ consumption as well as communication to family about healthy eating (Cunningham-Sabo \& Lohse 2013; Jarpe-Ratner et al. 2016). However, none of these interventions involved populations other than in the US, Europe, Australia and New Zealand (Battjes-Fries et al. 2016; Black et al. 2018; Caraher et al. 2013; Chen et al. 2014; Cunningham-Sabo \& Lohse 2013; Jarpe-Ratner et al. 2016). Due to the cultural differences between Western and Asian countries, interventions should be tailored to the needs of the population of interest (Barrera et al. 2013). Overall, there is a lack of high-quality interventions on childhood cooking programs, especially with a long-term effect on nutritional outcomes (Hersch et al. 2014).

KidChen Study implies the "kids in kitchen" study. The idea of KidChen Study is to allow children to obtain the first-hand experience in preparing their own healthy meals incorporating all 5 senses-touch, sight, taste, hearing and smell. This current protocol aimed to describe the design of KidChen Study, a hands-on healthy meal preparation intervention involving all the core food groups among Malaysian children.

\section{METHODS}

\section{Design, location and time}

KidChen Study is a randomized-controlled trial located at Kuala Lumpur, the national capital of Malaysia. The study location, Kuala Lumpur consists of various zones; Bangsar-Pudu, Sentul and Keramat. A zone will be randomly selected, and subsequently, two primary schools from the selected zone will be randomly assigned to either intervention or control group using Research Randomizer. Inclusion criteria include: (1) healthy Malaysian children aged 10-11 years; (2) can understand English/Malay language and with; (3) parent's informed consent and individual assent. Children with: (1) food allergies (e.g.: wheat/gluten, dairy or peanuts); (2) any serious diseases that require medical attention; (3) physically/mentally disabled children and/or; (4) are exposed to preparing healthy meals at home will be excluded.

\section{Sampling}

The sample size for present trial is determined using a formula by Chan (2003): $\mathrm{m}=\frac{2 c}{\delta^{2}}+1$, where $\mathrm{m}=$ size per group, $\mathrm{c}=7.9$ for $80 \%$ power, $\delta=\frac{\left|\mu_{2}-\mu_{1}\right|}{\sigma}$ is the standardised effect size, $\mu 1$ and $\mu 2$ are the means of the two treatment groups $\sigma$ is the common standard deviation $=\frac{S D_{1}^{2}+S D_{2}^{2}}{2} \mathrm{SD} 1$ and SD2 is the standard deviation for group 1 and 2 respectively. Based on a randomized-controlled trial by Fulkerson et al. (2011), SD1 and SD2 are 3.2. The sample size required for the present study is 32 per group. Taking into account of noncompliance and dropout rate of 50\% (Koo et al. 2018), the required sample size for each group is increased to 48; therefore, the total number is 96. Any children that wish to drop-out can do so, with the reasons being noted for documentation.

\section{Intervention framework and modules development}

KidChen Study is designed based on the Social Cognitive Theory (SCT) and experiential learning theory (Bandura 1999; Kolb et al. 2001). According to the SCT, learning occurs through social context with dynamic interactions between environmental factors (home food availability) and individual factors (knowledge, attitude and selfefficacy towards healthy meal preparation) that eventually influences an individual's behaviour (e.g. the practice of healthy meal preparation, dietary behaviour and food consumption pattern). As applied to KidChen Study, this theory holds that children's psychosocial factors and home food environment will influence their health related behaviour, in relation to their nutritional status.

Experiential learning theory involves processes where the learner actively experiences an activity, attempts to conceptualize what is observed, reflects on that experience and 
finally tries to plan for a forthcoming experience (Seel 2012). In KidChen Study, intervention children will experience hands-on healthy meal preparation continuously in which they acquire various skills such as self-reflection, problem solving and abstract thinking (Efstratia 2014). No nutrition intervention will be conducted for children and parents from the control group. However, for ethical reasons, delayed KidChen intervention modules will be conducted for the control group after the study has ended.

The content of current intervention modules was already developed and validated. It was designed using evidence-based nutrition information, comprising all the core food groups needed by children for healthy growth and development. Literature searches were conducted in scientific databases namely Google Scholar, PubMed, Science Direct and Scopus for development of the modules. Reports, research articles and books were referred to develop evidence-based modules. Each module comprises nutrition education and hands-on healthy meal preparation tasks, aimed to achieve the specific learning outcomes and objectives. Content validity of the intervention modules was established by 2 academicians in the nutrition field, an academician expert in child psychology, a primary school teacher, a parent of a 10- and 11-year old child and a nutritionist. The expert panels were selected due to their experience in the development of nutrition modules for children and/or experience in understanding children's behaviour. Content validity form was provided to each of the experts. Every expert was required to rate the modules to ensure that the modules are in line to achieve the specific objectives and learning outcomes set. Every module was rated based on content, language (sentence structure, readability) and design/layout with a score of 1 as poor (to reject), 2 as average (major revision) and 3 as good (minor/no revision). Suggestions were given to improve the module in terms of content, language and design. Feedbacks from the expert panels were discussed among the research team and necessary changes to the intervention modules were made accordingly.

\section{Data collection}

Assessment will be made at pre-, postintervention and a follow-up after 3 months. Outcomes measurements include children's psychosocial factors towards healthy meal preparation, home food availability, dietary behaviour, food consumption pattern and anthropometric measurement.

Children's psychosocial factors (knowledge, attitude, practice and self-efficacy) towards healthy meal preparation will be assessed using a validated, self-administered, guided questionnaire ( $\mathrm{Ng}$ et al. 2020a). Parents will receive a validated home food availability questionnaire (Couch et al. 2014; Glanz \& Steffen 2008; Marsh et al. 2003). Sociodemographic characteristics such as monthly household income, highest educational attainment in the family and parents' age are collected in the first section of the questionnaire. Subsequent information includes the availability of various fruits, vegetables, healthy and unhealthy foods at home during the past 1 week. Apart from those foods from the validated questionnaires, several fruits, vegetables and foods will be included, reflecting Malaysians' usual foods consumption (Institute for Public Health (IPH) 2014). The home food availability questionnaire was tested for internal consistency (unpublished data, $\mathrm{n}=200$, Cronbach's alpha $=0.72$ ).

Dietary behaviours namely breakfast consumption and fast food consumption will be self-reported using a guided questionnaire. The same questionnaire assessed children's food consumption pattern (frequency of usual food groups consumption). Questions are adapted, with consideration of Malaysian Dietary Guidelines for Children and Adolescents (Ainuki et al. 2013; Ministry of Health Malaysia 2013; Wilson et al. 2008). Children will be asked the number of times they consume breakfast, morning snack, lunch, afternoon snack, dinner and supper in a week, and the food groups that they usually consumed for each specific meal. They will be allowed to select more than one food group or none if they usually skipped their meals. Pictures and food models will be utilized to assist children.

Children's anthropometric measurements include height, weight, waist circumference, and Body Mass Index (BMI)-for-age. Height will be measured to the nearest $0.1 \mathrm{~cm}$ using portable stadiometer Seca 213. As the standard height measurement protocol, children will stand straight without shoes, head in Frankfurt plane, arms at side with palms facing the thighs, heels together and shoulder blades, buttocks and heels 
touching the vertical surface of the stadiometer (Gibson 2005). Tanita Body Composition Analyzer SC-330 will be used to measure body fat percentage and weight to the nearest $0.1 \mathrm{~kg}$. Children will stand straight barefooted in the center of the platform, looking straight ahead in light indoor clothing during measurement (Gibson 2005). Weight and height will be computed into body mass index-for age (BMI z-score) using AnthroPlus software as per World Health Organization (WHO) growth reference. Waist circumference will be measured to the nearest $0.1 \mathrm{~cm}$ over the skin midway between the tenth rib and the iliac crest at the end of normal expiration using a non-stretchable measuring tape and further classified using percentile charts for the Malaysian childhood population to define abdominal obesity (Poh et al. 2011). All measurements will be taken twice to obtain an average reading.

\section{Evaluation of KidChen intervention modules}

After each module, children will be given a set of questions for providing insights and evaluation of the intervention modules. The evaluation includes their overall acceptance of the storytelling/drama as well. Questions are developed and revised by the research team to ensure its simplicity, relevance and appropriateness for children and parents.

\section{Data analysis}

Statistical analysis will be conducted using Statistical Package for Social Science (SPSS) Version 20. Data will be entered, cleaned and checked before proceeding to data analysis. All variables will be tested for normality distribution. Categorical variables are presented as number (percentage), meanwhile continuous variables are reported as mean (standard deviation). The differences between intervention and control group's psychosocial factors towards healthy meal preparation, home food availability, dietary behaviour, food consumption pattern and anthropometric measurements will be assessed using independent $\mathrm{t}$-test. Differences within groups will be determined using dependent sample t-test. Association between categorical variables items will be determined using the Chisquare test. Repeated measures ANOVA will be used to determine will be used to determine the effectiveness of KidChen intervention on changes of psychosocial factors, home food environment, dietary behaviour, food consumption pattern and anthropometric measurements among children (within-group to assess the effect of time: pre-, post-intervention and 3-months follow up; and between-groups to assess the effect of groups: intervention versus control group). Significance value is set at $\mathrm{p}<0.05$.

\section{RESULT AND DISCUSSION}

This current protocol describes the design of KidChen Study, a hands-on healthy meal preparation intervention among children. To the best of our knowledge, KidChen Study could be the first family-based experimental study on hands-on healthy meal preparation involving all core food groups with the element of storytelling/ drama in nutrition education, aimed to improve the nutritional outcomes of children. The overview of KidChen intervention components is displayed in Table 1.

Table 2 displays the content validity of the intervention modules. All experts rated that the content and design of the modules are suitable (maximum score of 3 , good with minor revision). In terms of language, 3 and 2 experts rated that 'home is where the (healthy) food is' and 'vibrant vegetables' module respectively as average (score of 2 with major revision needed). Meanwhile, the remaining experts rated the modules as good with minor revision in terms of language. Subsequently, changes are made to the modules according to the panel's comments to ensure that the content is in line with the aim, language is simple and easy to understand, while the design is suitable for children.

Generally, the intervention consists of a home food environment module (parent-child session) and 5 hands-on healthy meal preparation sessions among children. The main basis of KidChen Study is to allow children to learn about foods through experience and incorporate the concept of having fun while learning through storytelling/drama. In addition, parental involvement is included as the gatekeeper of home food availability. Given that parents are responsible for the physical and social development of their child, parental involvement can potentially improve intervention effectiveness (Ritchie et al. 2005; Black et al. 2017). Table 3 displays the specific nutrition education topics 
Protocol of a healthy meal preparation intervention among children

Table 1. Overview of KidChen intervention component

Component Details

Home food environment mod- This is the first module for parents to come along with their child.

ules (parent-child)/“Home is $\quad 15$ minutes of interactive nutrition talk on the role of parents and where the (healthy) food is" home food availability

- 15 minutes of learning how to use food labels and food labels quiz (parent-child pair activity)

- 15 minutes of healthful food tasting (meal consisting of core food groups)

- 15 minutes of apron fitting, interactive food and kitchen safety talk

Hands-on healthy meal prepara- Five modules with a focus on a food group: (1) good grains; (2) power protion modules for children tein foods; (3) vibrant vegetables; (4) amazing dairy; (5) fit fruits; each consisting of 15 minutes of storytelling and drama related to nutrition principles, 30 minutes of hands-on activity and lastly, 15 minutes of meal sharing and discussion.

After each module, children will be given a nutrition booklet containing meal preparation information, recipe and healthful food ingredients to bring home, depending on the main food group of the module. Children will also receive a set of measuring cups and spoons.

incorporated during the storytelling/drama session and the hands-on healthy meal preparation activities for every module.

In KidChen Study, every children module begins with storytelling/drama using fictional characters to deliver nutrition education. Storytelling/drama is a simple yet powerful method in education (Seipel et al. 2014) that allows the essence of complex concepts to be conveyed in a meaningful and non-threatening manner (Suzuki et al. 2018). In KidChen Study, a main story is written which centres around kids' adventure to unlock various food groups. The main story is divided into 5 different parts, each representing a main food group whereby nutrition principles are incorporated into these stories to enhance learning and span throughout the 5 modules for children. Continuity element in the story is important to get the children excited for the following module and to remember the nutrition concepts. Helpers with a nutrition background will be assigned to various characters. Drama rehearsal will be conducted prior to the nutrition module to ensure that the drama/story would be an entertaining and educational for children. The duration of nutrition education and storytelling/drama sessions are 15 minutes as it was demonstrated that children typically have a short attention span (Bunce et al. 2010). Foods to be prepared by children will be hinted during drama session and at the end, it will be revealed to children their hands-on healthy meal preparation task for the session. The connection between storytelling/drama with the later handson healthy meal preparation activity was crucial for increasing curiosity in children and familiarity towards various foods.

As for the hands-on healthy meal preparation sessions, emphasis will be made on one specific food group according to the recipe's main ingredient. Food and kitchen safety are important factors to consider when implementing the hands-on sessions. Hence, children will be equipped with food and kitchen safety knowledge during the first module (parent-child session) and reinforced at every hands-on session. Besides, the hands-on sessions are designed from basic meal preparation tasks namely washing and serving food, to a higher level of using the knife, stirring hot foods and usage of equipment such as oven and blender. This will help children to learn from basic, before transitioning to tasks with increased difficulty. Additionally, children will participate in meal-related tasks with adult's supervision; guidance from one main moderator (certified food handler with nutrition background) and helpers with nutrition background (ratio of 1 helper: 5 children). It was shown that a ratio of 1 adult: 4 children were needed as reported by a previous study (Jarpe-Ratner et al. 2016). 
Table 2. The average score of every module rated by the expert panel

\begin{tabular}{|c|c|c|c|}
\hline \multirow{2}{*}{ Module } & \multicolumn{3}{|c|}{ Criteria } \\
\hline & Content & Language & Design \\
\hline $\begin{array}{l}\text { Home is where the } \\
\text { (healthy) food is }\end{array}$ & 3 & $2.5^{\mathrm{a}}$ & 3 \\
\hline Good grains & 3 & 3 & 3 \\
\hline $\begin{array}{l}\text { Power protein } \\
\text { foods }\end{array}$ & 3 & 3 & 3 \\
\hline Vibrant vegetables & 3 & $2.7^{\mathrm{b}}$ & 3 \\
\hline Amazing cairy & 3 & 3 & 3 \\
\hline Fit fruits & 3 & 3 & 3 \\
\hline $\begin{array}{l}\text { All modules were rate } \\
\text { based on the respective } \\
{ }^{a} \text { Three experts (academici } \\
\text { ent) rated the module with } \\
\text { ing experts rated the modu } \\
{ }^{b} \text { Two experts (academicia } \\
\text { the module with a score o } \\
\text { rated the module with a sc }\end{array}$ & $\begin{array}{l}\text { good (a } \\
\text { criteria by } \\
1 \text { in the nutr } \\
\text { score of } 2 \\
\text { with a scor } \\
\text { in the nutrit } \\
2 \text { (average) } \\
\text { re of } 3 \text { (goo }\end{array}$ & $\begin{array}{l}\text { maximum sc } \\
\text { all experts u } \\
\text { tion field, teac } \\
\text { average) while } \\
\text { of } 3 \text { (good) } \\
\text { on field and te } \\
\text { hile the remai }\end{array}$ & $\begin{array}{l}\text { ore of } 3 \\
\text { less stated } \\
\text { ler and par- } \\
\text { the remain } \\
\text { cher) rated } \\
\text { ing experts }\end{array}$ \\
\hline
\end{tabular}

Considering the feasibility factor in the number of nutrition helpers needed, level of children's understanding towards healthy meal preparation in needs assessment, group discussion from intervention subsample, we deemed a ratio of $1: 5$ as sufficient. Further, emphasis is made to encourage children to be advocates and leaders during the hands-on meal preparation activity and to guide each other as peer support, in line with SCT. Hence, too much assistance from an adult may not be suitable. In additions, helpers will be equipped with the programme flow, modules content and are trained prior to every module to ensure standardization in the method of delivery. During each module, helpers ensure that all children perform the hands-on activity as stated in a task checklist.

After each hands-on session, an ingredient from a specific food group is provided to encourage children to prepare meals using those ingredients with their parents. Providing children with free, accessible fruits and vegetables have been experimentally shown to positively affect long-term dietary behaviour due to increased exposure and preferences, thereby suggesting that this approach is worth pursuing (DeCosta et al. 2017). In the current study, such approach will be implemented comprehensively with the hands-on healthy meal preparation session, nutrition education (storytelling/drama) and parental involvement to improve effectiveness, as suggested earlier (Coyle et al. 2009). Past study has highlighted the facilitators in the provision of healthy ingredients, including sufficient funds and coordination among partners/suppliers (Bai et al. 2011). Therefore, it is highly recommended to involve stakeholders and partnerships link for the sustainability of such approach. In the present study, we are not only providing fruits and vegetables, but also other ingredients such as whole grains, seeds, nuts and dairy foods. While research usually emphasized fruits and vegetables as target foods (Van der Horst et al. 2014), children need a variety of food groups in their diet for healthy growth and development. Hence, we concentrate on all core food groups.

Previously, it was shown that nutrition education programs that have a long-term effect on dietary behavior are those that offer children the opportunity to engage with food in different ways and incorporating experiential, contextual knowledge and social networks, such as parents which allows nutrition knowledge and positive attitude towards healthy foods to be created (Chen et al. 2014; Dudley et al. 2015). In learning to cook, children can be empowered to prepare healthful meals, learn about ingredients, gain a strong sense of personal achievement and the knowledge that allows them to judge more healthful alternatives when eating away from home (Levy \& Auld 2004). Although it was reported that children had poor knowledge and practice towards healthy meal preparation $(\mathrm{Ng}$ et al. 2020b), they had positive attitude and selfefficacy, suggesting that hands-on healthy meal preparation is liked by children and could be a potential health-promotion strategy.

The National Nutrition Policy of Malaysia highlighted that good health goes beyond access to nutritious food and the nutrition knowledge to make informed and healthy dietary choices. In the same context, KidChen Study goes beyond providing knowledge by targeting long-term nutritional behavior change, equipping children with lifelong skills needed for healthy eating and includes the development of interactive educational modules on healthy eating for schoolchildren as outlined as priorities in National Plan of Action for Nutrition of Malaysia III 2016-2025. On an international level, KidChen Study is aligned with the 2030 Sustainable Development Goals (SDG) by United Nations and Global Nutrition Targets 
Protocol of a healthy meal preparation intervention among children

Table 3. Nutrition education topics and hands-on activities of KidChen intervention

\begin{tabular}{|c|c|c|}
\hline Module & Hands-on activities/skills & Nutrition education \\
\hline $\begin{array}{l}\text { Home is } \\
\text { where the food } \\
\text { (healthy) is }\end{array}$ & $\begin{array}{l}\text { - Interactive nutrition talk } \\
\text { - Quiz } \\
\text { - Apron fitting } \\
\text { - Healthy food tasting from various food groups }\end{array}$ & $\begin{array}{l}\text { - Role of parents home food availability } \\
\text { - Using the food labels } \\
\text { - Food safety } \\
\text { - Kitchen safety }\end{array}$ \\
\hline Good grains & $\begin{array}{l}\text { - Cooking demonstration: fried brown rice } \\
\text { - Food and kitchen safety: wearing proper attire and } \\
\text { washing hands } \\
\text { - Washing rice \& serving food } \\
\text { - Usage of rice cooker }\end{array}$ & $\begin{array}{l}\text { - "Suku-Suku Separuh" (quarter quarter half) } \\
\text { - Benefits of whole grains vs refined grains } \\
\text { - Source of whole grains }\end{array}$ \\
\hline $\begin{array}{l}\text { Power protein } \\
\text { foods }\end{array}$ & $\begin{array}{l}\text { - Assemble own sandwich (egg \& peanut butter } \\
\text { sandwich) } \\
\text { - Deciding own ingredients } \\
\text { - Basic knife skills (to spread peanut butter and cut } \\
\text { soft food) } \\
\text { - Usage of toaster }\end{array}$ & $\begin{array}{l}\text { - Protein (benefits) } \\
\text { - Source of plant \& animal protein } \\
\text { - Good fats } \\
\text { - Drawbacks of processed meat }\end{array}$ \\
\hline $\begin{array}{l}\text { Vibrant } \\
\text { vegetables }\end{array}$ & $\begin{array}{l}\text { - Touching and seeing real vegetables } \\
\text { - Following recipe directions and working in groups } \\
\text { - Washing vegetables } \\
\text { - Cutting vegetables (higher levels of knife skills- } \\
\text { cutting different textures of food) } \\
\text { - Measuring ingredients } \\
\text { - Boiling \& stirring food } \\
\text { - Using peeler, ladle and spatula }\end{array}$ & $\begin{array}{l}\text { - Vegetables for superkids (importance of veg } \\
\text { etables for health) } \\
\text { - Eat a rainbow of colours (benefits of different } \\
\text { colours of vegetables) }\end{array}$ \\
\hline Amazing dairy & $\begin{array}{l}\text { - Making smoothies } \\
\text { - Preparing ingredients (washing and cutting) } \\
\text { - Measuring ingredients } \\
\text { - Incorporating dairy into food preparation } \\
\text { - Usage of blender }\end{array}$ & $\begin{array}{l}\text { - Dairy (benefits) } \\
\text { - Source of dairy food } \\
\text { - Flavoured vs original dairy products } \\
\text { - Use of dairy in cooking } \\
\text { - Drawbacks of carbonated drinks } \\
\text { - Importance of breakfast }\end{array}$ \\
\hline $\begin{array}{l}\text { Fit fruits } \\
\text { (children) }\end{array}$ & $\begin{array}{l}\text { - Washing and cutting fruits } \\
\text { - Using muffin tray, muffin liner, baking powder and } \\
\text { baking soda } \\
\text { - Making dough } \\
\text { - Usage of oven } \\
\text { - Baking fruits muffins }\end{array}$ & $\begin{array}{l}\text { - Fruits (benefits) } \\
\text { - Different taste of fruits (sweet, sour, sweet \& } \\
\text { sour) and how to eat them } \\
\text { - Fresh fruits vs fruits drinks, canned fruits, fresh } \\
\text { fruit juice }\end{array}$ \\
\hline
\end{tabular}

2025 by World Health Organizations (WHO) to ensure healthy lives, promote well-being, improve nutritional status, and prevent obesity and non-communicable diseases. KidChen Study aims towards the common goals of SDG and WHO to empower vulnerable groups such as children and youth in providing support and to provide evidence of behavioural change from direct interventions which are keys for informing health and education policies.

We anticipate that this study will reveal the effectiveness of an innovative experiential learning strategy in improving the nutritional outcomes of children. Findings of KidChen Study is important to understand the approach of hands-on healthy meal preparation in affecting children's food-related attitude, behavior, in addition to providing insights on children's acceptance towards hands-on healthy meal preparation.

This innovative experiential learning approach including parent's support is based on scientific evidence and represents a way forward in nutrition education. We foresee that the 
output would be well-received on a national and international level. Since this is an ongoing study, research findings will be published elsewhere once data are collected and analyzed.

\section{TRIAL REGISTRATION}

The trial is registered at https://www. irct.ir/trial/40804 (IRCT20190626044024N1). Medical Research and Ethics Committee (MREC) has reviewed and approved the study protocol [NMRR-18-725-41268, KKM/NIHSEC/P18-815 (11)]. Approval to conduct the study in schools is obtained from the Ministry of Education Malaysia (MoE) and Kuala Lumpur Federal Territory Education Department [KPM.600-3/2/3 Jld 45 (91)]. With permission from principals of the selected primary schools, consent form and information sheet are provided to parents. The study has commenced.

\section{ACKNOWLEDGEMENT}

We would like to thank Centre of Excellence for Research, Value Innovation and Entrepreneurship (CERVIE) UCSI University for funding this research study (Proj-In-FAS-058).

\section{AUTHOR DISCLOSURES}

The authors have no conflict of interest.

\section{REFERENCES}

Ainuki T, Akamatsu R, Hayashi F, Takemi Y. 2013. Association of enjoyable childhood mealtimes with adult eating behaviors and subjective diet-related quality of life. J Nutr Educ Behav 45(3):274-278. https:// doi.org/10.1016/j.jneb.2012.11.001.

Bai Y, Feldman C, Wunderlich SM, Aletras SC. 2011. Process evaluation of the fresh fruit and vegetable program implementation in a New Jersey elementary school. J of Child Nut \& Management 35(2):11.

Bandura A. 1999. Social cognitive theory: An agentic perspective. Asian J Soc Psychol 2(1):21-41. https://doi.org/10.1111/1467839X.00024.

Banfield EC, Liu Y, Davis JS, Chang S, FrazierWood AC. 2016. Poor adherence to US dietary guidelines for children and adolescents in the national health and nutrition examination survey population. $\mathrm{J}$ Acad Nutr Diet 116(1):21-27. https://doi. org/10.1016/j.jand.2015.08.010.

Barrera MJ, Castro FG, Strycker LA, Toobert DJ. 2013. Cultural adaptations of behavioral health interventions: A progress report. J Consult Clin Psychol 81(2):196-205. https://doi.org/10.1037/a0027085.

Battjes-Fries MCE, Haveman-Nies A, Van Dongen EJI, Meester HJ, Top-Pullen RVD, De Graaf K,Van't Veer P. 2016. Effectiveness of taste lessons with and without additional experiential learning activities on children's psychosocial determinants of vegetables consumption. Appetite 105:519-526. https://doi. org/10.1016/j.appet.2016.06.016.

Black AP, D'Onise K, McDermott R, Vally H, O'Dea K. 2017. How effective are family-based and institutional nutrition interventions in improving children's diet and health? A systematic review. BMC Public Health 17(1):1-19. https://doi. org/10.1186/s12889-017-4795-5.

Black K, Thomson C, Chryssidis T, Finigan R, Hann C, Jackson R, Robinson C, Toldi O, Skidmore P. 2018. Pilot testing of an intensive cooking course for New Zealand adolescents: The create-our-own kai study. Nutrients 10(5):556. https://doi. org/10.3390/nu10050556.

Bunce DM, Flens EA, Neiles KY. 2010. How long can students pay attention in class? A study of student attention decline using clickers. J Chem Educ 87(12):1438-1443. https://doi.org/10.1021/ed100409p.

Caraher M, Seeley A, Wu M, Lloyd S. 2013. When chefs adopt a school? An evaluation of a cooking intervention in English primary schools. Appetite 62:50-59. https://doi. org/10.1016/j.appet.2012.11.007.

Chan YH. 2003. Randomised controlled trials (RCTs)-sample size: The magic number? Singapore Med J 44(4):172-174.

Chen Q, Goto K, Wolff C, Bianco-Simeral S, Gruneisen K, Gray K. 2014. Cooking up diversity. Impact of a multicomponent, multicultural, experiential intervention on food and cooking behaviors among elementary-school students from lowincome ethnically diverse families. 
Protocol of a healthy meal preparation intervention among children

Appetite 80:114-122. https://doi. org/10.1016/j.appet.2014.05.009.

Couch S, Glanz K, Zhou C, Sallis JF, Saelens BE. 2014. Home food environment in relation to children's diet quality and weight status. J AcadNutrDiet 114(10):1569-1579.https:// doi.org/10.1016/j.jand.2014.05.015.

Coyle KK, Potter S, Schneider D, May G. Robin LE, Seymour J, Debrot K. 2009. Distributing free fresh fruit and vegetables at school: Results of a pilot outcome evaluation. Public Health Rep 124(5): 660-669. https://doi. org/10.1177/003335490912400508.

Cunningham-Sabo L, Lohse B. 2013. Cooking with kids positively affectsfourth graders' vegetable preferences and attitudes and self-efficacy for food and cooking. Childhood Obesity 9(6):549-556. https:// doi.org/10.1089/chi.2013.0076.

DeCosta P, Møller P, Frøst MB, Olsen A. 2017. Changing children's eating behaviour - a review of experimental research. Appetite 113:327-357. https://doi.org/10.1016/j. appet.2017.03.004.

Dudley DA, Cotton WG, Peralta LR. 2015. Teaching approaches and strategies that promote healthy eating in primary school children: A systematic review and metaanalysis. Int J Behav Nutr Phy 12(1):28. https://doi.org/10.1186/s12966-015-01828.

Efstratia D. 2014. Experiential Education through Project Based Learning. Procedia Soc Behav Sci 152:1256-1260. https://doi. org/10.1016/j.sbspro.2014.09.362.

Evans CEL, Christian MS, Cleghorn CL, Greenwood DC, Cade, JE. 2012. Systematic review and meta-analysis of school-based interventions to improve daily fruit and vegetable intake in children aged 5 to $12 \mathrm{y}$. Am J Clin Nutr 96(4):889-901. https://doi. org/10.3945/ajcn.111.030270.

Faught EL, Montemurro G, Storey KE, Veugelers PJ. 2017. Adherence to dietary recommendations supports Canadian children's academic achievement. Can J diet Pract Res 78(3):102-108. https://doi. org/10.3148/cjdpr-2017-008.

Febriani D, Sudarti T. 2019. Fast food as drivers for overweight and obesity among urban school children at Jakarta, Indonesia. J
Gizi Pangan 14(2):99-106. https://doi. org/10.25182/jgp.2019.14.2.99-106.

Fulkerson JA, Rydell S, Kubik MY, Lytle L, Boutelle K, Story M, Neumark-Sztainer D, Dudovitz B, Garwick A. 2011. Healthy home offerings via the mealtime environment (HOME): Feasibility, acceptability, and outcomes of a pilot study. Obesity 18(S1): S69-S74. https:// doi.org/10.1038/oby.2009.434.

Gibson RS. 2005. Principles of Nutritional Assessment. 2nd ed. New York (USA): Oxford University Press.

Glanz K, Steffen A. 2008. Development and reliability testing for measures of psychosocial constructs associated with adolescent girls' calcium intake. J Am Diet Assoc 108(5):857-861. https://doi. org/10.1016/j.jada.2008.02.014.

Hersch D, Perdue L, Ambroz T, Boucher JL. 2014. The impact of cooking classes on food-related preferences, attitudes, and behaviors of school-aged children: A systematic review of the evidence, 20032014. Prev Chronic Dis 11:140267. doi: 10.5888/pcd11.140267.

Hoque KE, Kamaluddin MA, Abdul Razak AZA, Wahid AAA. 2016. Building healthy eating habits in childhood: A study of the attitudes, knowledge and dietary habits of school children in Malaysia. PeerJ 4: e2651.

[IPH] Institute for Public Health. 2014. National Health and Morbidity Survey 2014: Malaysian Adult Nutrition Survey (MANS). Volume 1 Methodology and General Findings. Kuala Lumpur (MA): Ministry of Health Malaysia

Jarpe-Ratner E, Folkens S, Sharma S, Daro D, Edens NK. 2016. An experiential cooking and nutrition education program increases cooking self-efficacy and vegetable consumption in children in grades 3-8. J Nutr Educ Behav 48(10):697-705. https:// doi.org/10.1016/j.jneb.2016.07.021.

Kolb DA, Boyatzis RE, Mainemelis C. 2001. Experiential Learning Theory: Previous Research and New Directions. In: $\mathrm{R}$ Sternberg and L Zhang, eds. Perspectives on Thinking, Learning, and Cognitive Styles. The Educational Psychology Series. New Jersey (USA): Lawrence Erlbaum Associates Inc. 
Koo HC, Poh BK, Abd Talib R. 2018. The great-child ${ }^{\mathrm{TM}}$ trial: A quasi-experimental intervention on whole grains with healthy balanced diet to manage childhood obesity in Kuala Lumpur, Malaysia. Nutrients. 10(2):156. https://doi.org/10.3390/ nu10020156.

Levy J, Auld G. 2004. Cooking classes outperform cooking demonstrations for college sophomores. J Nutr Educ Behav 36:197-203. https://doi.org/10.1016/ S1499-4046(06)60234-0.

Marsh T, Cullen KW, Baranowski T. 2003. Validation of a fruit, juice, and vegetable availability questionnaire. J Nutr Educ Behav 35(2):93-97. doi: https://doi. org/10.1016/S1499-4046(06)60045-6.

Ministry of Health Malaysia. 2013. Malaysian Dietary Guidelines for Children and Adolescents. National Coordinating Committee on Food and Nutrition. https://books.google. com.my/books/about/Malaysian Dietary_Guidelines_for_Childre. $\mathrm{html}$ ?id $=\overline{\mathrm{K}}$ O8NrgEACAAJ $\&$ redir esc $=\mathrm{y}$ [Accessed 13rd May 2017].

$\mathrm{Ng}$ CM, Koo HC, Firdaus M, Yap RWK, Chong PN, Kaur S. 2020a. Development, validity and reliability of questionnaire to measure children's psychosocial factors towards healthy meal preparation. Journal Public Health 28(2):155-161. https://doi. org/10.1007/s10389-019-01060-w.

$\mathrm{Ng}$ CM, Satvinder K, Koo HC, Yap RWK, Mukhtar F. 2020b. Children's psychosocial factors of healthy meal preparation as predictors for nutritional status measures. International Journal for Vitamin and Nutrition Research May 28:1-9. doi: 10.1024/0300-9831/a000655.

Poh BK, Jannah AN, Chong LK, Ruzita AT, Ismail MN, McCarthy D. 2011. Waist circumference percentile curves for Malaysian children and adolescents aged 6.0-16.9 years. International Journal of Pediatric Obesity 6(3-4):229-235.

Rankin J, Matthews L, Cobley S, Han A, Sanders R, Wiltshire HD, Baker JS. 2016. Psychological consequences of childhood obesity: Psychiatric comorbidity and prevention. Adolescent Health Med Ther 7: 125-146. doi: 10.2147/AHMT.S101631.

Ritchie LD, Welk G, Styne D, Gerstein DE, Crawford PB. 2005. Family environment and pediatric overweight: What is a parent to do? J Am Diet Assoc 105(5):70-79. https:// doi.org/10.1016/j.jada.2005.02.017.

Seel NM. 2012. Encyclopedia of the Sciences of Learning. New York (USA): Springer Science \& Business Media.

Seipel B, Carlson SE, Bianco-simeral S, Frigaard M, Wolff C, Goto K. 2014. The nutritional moral of the story: An examination of storybooks used to promote healthy food-choice behavior. Psychology and Education: An Interdisciplinary Journal 51(3-4):30-41.

Suzuki WA, Feliú-Mójer MI, Hasson U, Yehuda R, Zarate JM. 2018. Dialogues: The science and power of storytelling. $\mathrm{J}$ Neurosci 38(44):9468-9470. https://doi. org/10.1523/JNEUROSCI.1942-18.2018.

Swinburn BA, Sacks G, Hall KD, McPherson K, Finegood DT, Moodie ML, Gortmaker SL. 2011. The global obesity pandemic: Shaped by global drivers and local environments. The Lancet 378(9793):804-814. https:// doi.org/10.1016/S0140-6736(11)60813-1.

The Academy of Medical Sciences. 2017 Addressing the Global Health Challenge of Obesity in Malaysia. Kuala Lumpur (MA): The Academy of Medical Sciences.

Uijtdewilligen L, Waters $\mathrm{CN}$, MüllerRiemenschneider F, Lim YW. 2016. Preventing childhood obesity in Asia: An overview of intervention programmes. Obesity Reviews 17(11):1103-1115. https://doi.org/10.1111/obr.12435.

Van der Horst K, Ferrage A, Rytz A. 2014. Involving children in meal preparation. Effects on food intake. Appetite 79:18-24. https://doi.org/10.1016/j. appet.2014.03.030.

Wilson AM, Magarey AM, Mastersson N. 2008. Reliability and relative validity of a child nutrition questionnaire to simultaneously assess dietary patterns associated with positive energy balance and food behaviours, attitudes, knowledge and environments associated with healthy eating. Int J Behav Nutr Phy Act 5(5):5155.https://doi.org/10.1186/1479-5868-5-5.

[WHO] World Health Organization. 2018. Obesity and overweight. https://www. who.int/en/news-room/fact-sheets/detail/ obesity-and-overweight [Accessed 9th May 2019]. 